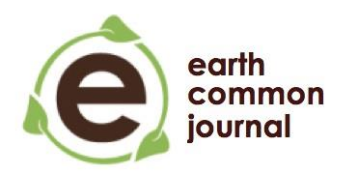

Earth Common Journal

Convergence

MacEwan University

Volume 5, Number 1, September 2015

\title{
Article
}

\section{Fire for Well-Being: Use of prescribed burning in the Northern Boreal Forest}

\author{
Chantal Roy Denis \\ MacEwan University, Canada
}

\begin{abstract}
Aboriginal peoples of the Northern Alberta Boreal Forest have used fire knowledge and burning practices to maintain their environment for generations. Prescribed burning is vital to Aboriginal peoples' relationships with the environment, and was essential to their hunting and gathering subsistence. Research has been limited on Aboriginal peoples' use of fire not only to manage resources but to maintain their health and well-being. The research paper suggests that burning also allowed management of these medicinal plants. Such plants growing in open clearings or near water such as streams, rivers, or lakes were fired in order to maintain and manage Aboriginal peoples' health and well-being in the boreal forest.
\end{abstract}




\section{Introduction}

As spring approaches, the Stoney Nakoda First Nation work with Alberta Environment to burn the dry grasses on their reserve. The intentional burning of the dry grasses is necessary to renew them and other plants, while also protecting the community from possible wildfires (Derworiz, 2015). Prescribed burning is not a recent practice; it has been used for generations by Aboriginal peoples. Typically burning is done in the spring, when snow remains in the forest; the damp and snowy areas in the dense forest act as barriers to control the fire (Lewis \& Ferguson, 1998, p.69-70). Similarly, fire in Alberta's northern boreal forest has typically been used for managing build-up of fuels, creating firebreaks, and spurring quick growth of shrubs and grasses. Fire ecology in the boreal forests was understood by Aboriginal peoples as vital to their relationship with the environment, as controlled burning was essential to their hunting and gathering subsistence (Lewis, 1982, p. 17).

As Lewis's (1982) extensive research on prescribed burning notes: "Prescribed fires were once part of the Indian's own pattern of 'landscape management"' (p. 17). Indeed, the boreal forest animal and plant species rely on prescribed burning. For example, muskrat and beaver habitats are associated with recently burned areas (p. 16). Although extensive research exists on the use of fire to manage hunting and gathering resources for sustenance, little is available on its use to maintain Aboriginal health and well-being. In addition to managing hunting and gathering resources, burning allowed management of medicinal plants. Such plants grow in open clearings or near streams, rivers, or lakes. In firing these locations, Aboriginal peoples of the boreal forest were also maintaining and managing their health. Berries were an essential food source and provided helpful vitamins and nutrients, as well as medicine. Burning around camps managed bothersome pests such as ticks, flies and mosquitoes. While burning is commonly done by men, women used fire to burn berry bushes as needed. By exploring the use of fire for plant management, it is evident that women played a key role in maintaining the overall health of the community.

The research sheds light on women's use of fire, specifically for the comfort of their family and community. It further proposes that fire was used to maintain precious plant resources for Aboriginal peoples of the boreal forest to manage their health and overall well-being.

Many Aboriginal peoples call the northern Alberta boreal forest home, including the Dene (Slavey), Chipewyan, Woodland Cree, and the Métis. The physical ecology of the boreal forest is of low lying land, with ranges of low hills covered by dense forests of 
spruce, tamarack, birch, poplar and willow. There are numerous interconnected streams, rivers and lakes. Aboriginal peoples maintain biodiversity throughout the boreal forest by burning and thus creating open areas (Boag, February 26, 2015). Rich with resources, it provides habitats for large game such as moose, caribou, and deer, as well as smaller game such as rabbits. The waterways attract fowl such as ducks, and geese, and are home to beavers and muskrat. Aboriginal peoples developed long-standing traditional knowledge from their relationship with the environment. Game such as moose is central to the traditions and culture of Aboriginal communities in the boreal forest (Nelson, Natcher, \& Hickey, 2005, p. 290). Harvest regimes are based on predictable seasons. For example, September and October are moose hunting seasons, while bears are hunted in late summer as they forage along rivers (p. 290). Berries and other plants are harvested once ripe in mid to late summer. To increase the yield and cultivation potential of plants, it is important to create a mosaic of habitats (McAdoo, Schultz, \& Swanson, 2013, p. 248). Several mosaic habitats ensure a diversity of species throughout the landscape, thus increasing biodiversity and food security. Fire is key in maintaining the relationship between Aboriginal peoples, animals and plants in the resource rich boreal forest of northern Alberta.

\section{Managing Medicinal Plants}

Aboriginal peoples know the importance of human and plant relationships. The relationship functions whereas "the plant world in turn provides the animal's world with its sustenance, and we, as human beings, exist only because of the kinship that exists between all of us" (Belcourt, 2007, p. 2). The use of plants has always been part of Aboriginal peoples' lives as a source of food and medicine. The plants are also a source of food for animals, such as berries for bears. This symbiotic relationship is one based on respect. This relationship requires the use of fire to rejuvenate plants, and the plants in turn provide their medicinal and nutritional value. Fire is a tool, and the skill is passed down by generational learning. Medicinal plant knowledge is passed down generationally, typically from a community Elder with specialized knowledge of plant properties. For the Pikangikum in the Ontario boreal forest, "knowledge and relationship of fire is by no means limited to its potential role in managing vegetation at the scale of sites but includes knowledge of fire as it occurs at both smaller and larger scales" (Miller \& Davidson-Hunt, 2010, p. 402). Burning is management of the environment, ensuring an abundance of plant and animal species. Seasonal burning creates a mosaic of successional stages in the environment, allowing for different stages of growth to exist and thus greater biodiversity (Lewis \& Ferguson, 1998, p. 59). 
Burning signifies respect for the symbiotic relationship developed between Aboriginal peoples and their environment. For Métis Elder Rose Richardson, respect is paramount because without it plants "would hide from certain people, or they would simply relocate if they were not respected" (Belcourt, 2007, p. 10). For Aboriginal peoples in the northern boreal forest, burning is a means of maintaining health. Cree Elder Eva Nanooch from Fox Creek Reserve recalls, "We didn't need any pills. If we were sick, there were lots of herbs. There's a plant for everything" (Meili, 1991, p. 121). Maintaining the landscape through burning is a technique to maintain the valuable medicinal plants.

Burning creates open areas where plant and animal biodiversity thrive. Employment of yards and corridors in the Canadian north, as stated by Lewis and Ferguson (1998), are created by prescribed burning as a key feature of hunting-gathering technologies (p. 74). Yards and corridors are areas such as meadows, streams, sloughs, lakeshores and even trails. In the dense boreal forest, these areas capture more sunlight, and plants are protected from becoming overtaken by encroaching trees and shrubs. Removing the forest canopy increases productivity of plants such as cow parsnip and stinging nettle (Turner, Davidson-Hunt, \& O'Flaherty, 2003, p. 448). Rose Cheecham, a knowledgeable practitioner of Cree bush land medicine, commonly picked cow parsnip for its medicinal purposes (Garvin, 1992, p. 73). In locations with reduced forest canopy, plants thrive, especially those used for medicinal purposes. Elder Ella Green recalls her mother taking her along the shoreline to pick plants, where she passed on knowledge of medicines (Berkes, 2012, p. 112). Maintaining the clearings, yards, and corridors allows a greater predictability of plant resources. Most importantly, these clearings create ecological edges. An ecological edge is a junction between forest, creeks, or clearings; they are zones of transition from one ecosystem to another. Edges are rich with a variety of plant species. These edges are vital in yielding important nutrient rich resources that support health and well-being (Turner, Davidson-Hunt, \& O'Flaherty, 2003, p. 444). For example, marshy areas between land and water "provided manomin (Zizania aquatica), as well as waterfowl, sweetflag (Acoris calamus), and waterlilies (Nymphaea tetragona) for medicine" (p. 445). Along riverbanks, fireweed and ginseng are abundant after a disturbance (Berkes \& DavidsonHunt, 2006, p. 35).

Fireweed has long been used by Aboriginal peoples. The plant has anti-inflammatory properties, and is rich in beta-carotene and Vitamins A and C (Belcourt, 2007, p. 26). An Elder from northern Alberta recalls using poplar tree sap mixed with spruce needles to make a poultice to treat open wounds (Garvin, 1992, p. 19). Another Elder recalls that a poplar tree skinned from the south side with the inside bark removed and chewed treats a cut while reducing swelling and scarring (Meili, 1991, p. 136). She recalls picking 
rosehips, which were frozen and made available year round for its vitamins and nutrients (Garvin, 1992, p. 61). In the Great Basin in the United States, Aboriginal peoples used fire not only to support renewed growth but to fireproof (McAdoo, Schultz, \& Swanson, 2013, p. 244).

It is commonly known that Aboriginal peoples in the boreal forest fireproofed their camps but little evidence was found indicating that they fireproofed in order to protect certain plants. However, it is likely that similar practices were possible in the boreal forest. Overall, burning for the maintenance of medicinal plants was an essential practice for Aboriginal peoples in managing health and illness. Understanding the importance of ecosystem management by Aboriginal peoples is essential to maintaining long term forest and its residents' health.

Certain plants are more abundant in some habitats, whereas others are abundant throughout the landscape. Berkes and Davidson-Hunt investigated the spread of plants in the boreal forest of Ontario to determine if certain plant habitats were more important to the Aboriginal peoples than others. They discovered that the Anishnaabe did not believe some plants to be more important than others (Berkes \& Davidson-Hunt, 2006, p. 41). For the Anishnaabe, maintaining overall biodiversity is essential, especially for medicinal plants. An Anishnaabe Elder revealed the importance of biodiversity when she explained the process of healing through plants: "Sometimes you are sick...they give you that medicine, or they tell you about these plants to go and pick...so you can get healed" (p. 42).

These sustainable practices are evident in other Aboriginal communities in the boreal forest. Plant medicinal qualities prescribed for an ill person are often specific to that person. The Elder receives knowledge of the plant needed to heal an individual through dreams, visions or fasting (Belcourt, 2007, p. 4). It is therefore essential to maintain an entire range of plants in the environment, as they may acquire knowledge of its healing powers when needed. According to Métis Elder Rose Richardson, "all plants have a purpose for either us or animal life" (p. 6). Biodiversity is achieved by using prescribed burning to create yards, corridors, clearings, and access around lakes, streams, and rivers, which support different habitats where diverse species flourish. The method encourages growth and fosters optimum habitat conditions (Kuhnlein \& Turner, 1991, p. 18). For example, the Anishnaabe believe that "as was, as is", meaning that all that is on the land should be here today and tomorrow (Berkes \& Davidson-Hunt, 2006, p. 42). Maintaining biodiversity is essential for Aboriginal peoples in the boreal forest because it ensures the availability of plants resources. 


\section{Berry Bushes: Medicines, Nutrients, Vitamins}

The northern boreal forest is home to many fruit-bearing trees and plants (Garvin, 1992, p. 88). Varieties such as pincherries, red currants, black currants, strawberries, raspberries, gooseberries, and blueberries are all available. Prescribed burning was commonly done by men, however, Lewis (1982) discovered from a Dene woman that women commonly fired berry patches (p. 40). Burning of berry bushes reveals women's role in managing their community's health. The burning of berry patches is a common practice among many Aboriginal peoples of North America. In the Great Basin region of the United States, it is documented that burning berry patches was common practice. In fact, it is a form of crop management; a method to ensure higher yields and promote food security (McAdoo, Schultz, \& Swanson, 2013, p. 244).

Examination of Aboriginal peoples' burning of non-timber forest products such as berry patches reveals the importance of maintaining plant resources. For example, in the boreal forest, burning of blueberry patches is done every few years to renew them but also to control succession (Berkes \& Davidson-Hunt, 2006, p. 39). By burning different patches at different times, succession of berry patches allows seasonal availability of berries. Given that berry patches begin producing berries approximately three years after burning, other patches burned in the interim would come into full productivity (Turner, Davidson-Hunt, \& O'Flaherty, 2003, p. 446). If the blueberry patch is not burned it will revert back to the forest. Blueberries contain high levels of antioxidants and Vitamin A and C. High in nutritional value and deliciously sweet, they are a key food source in the boreal forest. Many berries provide large amounts of other nutrients such as calcium and folic acid (Kuhnlein \& Turner, 1991, p. 11). Berries are dried and kept year round. They are ground up and added to variety of food dishes. They attract and maintain animal populations that enjoy them such as bears and birds. Blueberries are also used for medicine. Once prepared in a tea it is drunk to treat diarrhea, gargled to sooth sore throats, or relieve colic in children (Belcourt, 2007, p. 19-20). Beverages are commonly prepared from plants including wild mint, wild rose and blackberry to be taken as medicine, or as a regular beverage to support health (Kuhnlein \& Turner, 1991, p. 15). Food security and

yields are vital for treating ailments and ensuring good health. Therefore, berry patches are maintained not only for human and animal consumption, but for their nutritional value and medicinal purposes.

\section{Containing Pest Populations}

In addition to maintaining medicinal plants, prescribed burning provides other ways to ensure well-being in the boreal forest. Not only does burning replenish and re- 
invigorate essential plant resources, but it allows easy access to retrieve them by creating corridors and trails through the dense boreal forest. Burning around lakes, streams and rivers permits access to many important plant species in these edges, such as picking rat root in marshy areas. Prescribed burning ensures availability of medicinal plants in times of future need, and allows comfort in knowing medicinal resources are available. A comfortable life in the boreal forest also meant maintaining pest populations. Burning manages the bothersome flies and bugs. Burning around a camp or settlement reduces the black flies and mosquitoes (Lewis, 1982, p. 43). Firing around the camp keeps grasses low, thus allowing a breeze to pass through the camp which keeps pests away. If the camp is near water, burned grasses permit cool breezes to come off the water and control the bugs (Garvin, 1992, p. 43; Berkes, \& Davidson-Hunt, 2006, p. 40). Firing reduces tick populations which lay their eggs in the spring plant litter such as decomposing leaves, bark, needles, and grasses (Boag, 2015). In the past, fires were always started by lighting a slow burning substance. In the boreal forest, a fungal parasite growth is picked from fallen birch trees. The parasite growth is lit and kept nearby to repel insects (Garvin, 1992, p. 45-46). A Dene Elder recalls the pesky mosquitoes in the summer. Her mother would make a fire in a pail and carry it with them to keep the mosquitoes away (Meili, 1991, p. 92-93). Maintaining the pest populations allows Aboriginal peoples to live a more comfortable life in the boreal forest. A more comfortable life translates into well-being and overall health of boreal forest residents.

\section{Conservation of Medicinal Plants}

Medicinal plants and their acquired knowledge is sacred to the Aboriginal peoples of the boreal forest. People gain medicinal knowledge from Elders; however, it may take an entire lifetime, as it is not "the type of knowledge that can be handed down in one afternoon" (Belcourt, 2007, p. 4). As such, plant resources and the knowledge to use them are managed by Aboriginal peoples with their own conservation methods. As Aboriginal peoples developed a symbiotic relationship with plant and animals species in their environment, they developed conservation practices based on respect. The first step in conservation is to pass along the knowledge to future generations, to ensure it is never lost. Elder Ella Green recalls her aunties taking her into the bush to teach her about the different kinds of plants and their medicinal uses (Berkes, 2012, p. 112). In addition to conservation of knowledge, plants are only collected in a manner that ensures their continued productivity (Uprety, Asselin, Dhakal, \& Julien, 2012, p. 7). Prescribed burning ensures this optimum level of plant species. But only one-tenth of medicinal plants were picked (Belcourt, 2007, p. 10). Sites were never picked clean. As a form of respect, Aboriginal peoples took only what they needed without excess. This assured that enough 
was left to propagate for future availability. Aboriginal peoples always thanked the plant's spirit, as the plant gave its life to prolong the lives of others (p. 5). To show one's respect, when a plant is taken, an item is always offered in return, such as tobacco. All parts of the plant are used, nothing is wasted. The plant parts are used to prepare a variety of remedies to treat illnesses. The roots, rhizomes, stem, bark, leaves, flowers, fruits, young shoots, and whole plants were used to make poultices, powders, teas, and pastes (Uprety, Asselin, Dhakal, \& Julien, 2012, p. 5-6). Aboriginal peoples develop practices in sync with their landscape to ensure continuous abundance of plants. Aboriginal peoples' burning practices and respect for the environment ensures their improved and future well-being in the boreal forest.

\section{Future Conservation}

Conservation of medicinal plants and berry patches is a concern for Aboriginal peoples. Increasingly, traditional berry patches are lost due to the drying and clearing of land associated with development (Parlee, Geertsema, \& Willier, 2012, p. 7). The biggest threat to medicinal plants is the loss of habitation, specifically from human development (Uprety, Asselin, Dhakal, \& Julien, 2012, p. 7). As the entire ecosystem is based on interrelated relationships, destruction of berry patches may also result in devastating effects for the birds and bears that rely on them for food. Plant and animal habitats are increasingly becoming threatened by clearcut logging, strip mining, and large-scale agriculture (Kuhnlein \& Turner, 1991, p. 21). Mining for resources, especially the oil development in the north, has left many fearing the ecosystem is no longer healthy. Conservation approaches have focused less on the importance of medicinal plant resources. Furthermore, ethnobotanical studies on medicinal plants are scarce. Uprety, Asselin, Dhakal, and Julien (2012) attribute such little study in the area due to Aboriginal peoples' reluctance to share their knowledge (p.7). Aboriginal peoples' concerns derive from fear that profit-seeking pharmaceutical companies - without acknowledging or involving communities - will take their knowledge (p. 7). Elder Richardson, expresses her concerns, stating that "information is taken from our people and it becomes patented and copyrighted... as industry moves further north we are beginning to lose control of land on which our medicines grow" (Belcourt, 2007, p. 4).

Concern grows that with fewer Aboriginal peoples living full-time in the bush, medicinal knowledge will be completely lost. Elder Richardson further explains that: "...land has to be set aside to preserve these medicines, and to allow them to grow in their natural environment. We are people of the land. We must remain protectors of the land" (Belcourt, 2007, p.10). 
More research and attention should be allocated to conservation efforts of medicinal plants and other plant resource destruction in the boreal forest. Conservation methods must acknowledge and partner with local Aboriginal groups to work towards monitoring and managing the land.

\section{Conclusion}

The health and well-being of Aboriginal peoples in the northern boreal forest relies on the health and well-being of the forest and all species within it. For many Aboriginal peoples, maintaining health means "living in harmony with our natural surroundings and understanding our existence as a relational part to the rest of our mother earth. In taking care of our earth, we are taking care of ourselves" (Settee, 2011, p. 28). Aboriginal peoples in the boreal forest modified their environment with the proven method of prescribed burning. Prescribed burning is necessary for hunting and gathering resources, using medicinal plants, supporting berry bush growth, and riding the area of pests. Women engaged in habitat management of these plants in order to curb health crises. Aboriginal women retain a central role as community organizers, planners and leaders (p. V). As such, Aboriginal women's activities correspond to their important role of maintaining their family and community health by upholding traditional medicinal plants, berry patches and overall comfort. Women learn medicinal knowledge from the generation before them.

The diverse use of fire reveals the importance of maintaining a comfortable, healthy life in the boreal forest. By the early twentieth century, legislation and regulations curbed Aboriginal prescribed burning practices. These remain in place today, requiring Aboriginal communities to apply for permits prior to practicing traditional burning. As per Alberta Environment and Sustainable Resource Development First Nation communities require fire permits and must plan a prescribed fire with their local prevention officer (ESRD Website, 2013). As per Section 20 of the Forest and Prairie Protection Act, a permit granted may just as quickly be cancelled. A fire started without a permit is punishable by fines. Although government is attempting to coordinate efforts, Aboriginal communities continue to pursue government to recognize their prescribed burning practices. While fewer Aboriginal people live in the bush, efforts are being made, especially by community Elders, to strengthen their traditional knowledge for future generations. 
* Author: Chantal Roy Denis completed the Bachelor of Arts program at MacEwan University in 2015. A Métis women originally from St. Louis-Batoche, Saskatchewan with deep rooted passion and respect for Aboriginal histories and traditions. She is attending Graduate Studies at the University of Alberta in Fall 2015.

\section{References}

Alberta Environment and Sustainable Resource Development. (2013). Prescribed Burning. Retrieved from http://www.wildfire.alberta.ca/prescribed-fires/default.aspx.

Belcourt, C. (2007). Medicines to help us: Traditional Métis plant use. Saskatoon: Gabriel Dumont Institute

Berkes, F. (2012) Sacred ecology. Third Edition. New York: Routledge.

Berkes, F., \& Davidson-Hunt, I. J. (2006). Biodiversity, traditional management systems, and cultural landscapes: examples from the boreal forest of Canada. International Social Science Journal, 58 (187), 35-47.

Boag, F. (2015, February 26). Anthropology 399: Ecological Perspectives, Class Lecture. MacEwan University.

Boag, F. (2015, March 7). Anthropology 399: Ecological Perspectives, Class Lecture. MacEwan University.

Derworiz, C. (2015, January 27). Fire crews get head start on season with prescribed burn. Calgary Herald. Retrieved from http://calgaryherald.com/news/localnews/fire-crews-get-head-start-on-season-with-prescribed-burn.

Garvin, T. (1992). Bush land people. Calgary: Arctic Institute of North America of the University of Calgary.

Kuhnlein, H.V., \& Turner, N.J. (1991). Traditional plant foods of Canadian indigenous peoples: Nutrition, botany, and use. Food and Nutrition in History and Anthropology Volume 8. Philadelphia: Gordon and Breach.

Lewis, H.T., \& Ferguson, T.A. (1998). Yards, corridors, and mosaics: How to burn a boreal forest. Human Ecology, 16 (1), 57-77. 
Lewis, H.T. (1982). A time for burning. Edmonton: Boreal Institute for Northern Studies, University of Alberta.

McAdoo, K., Schultz, B.W., \& Swanson, S.R. (2013). Aboriginal precedent for active management of sagebrush-perennial grass communities in the great basin. Rangeland Ecology \& Management, 66 (3), 241-253.

Meili, D. (1991) Those who know: Profiles of Alberta's native elders. Edmonton: NeWest Press.

Miller, A.M., \& Davidson-Hunt, I.J. (2010). Fire, agency and scale in the creation of aboriginal cultural landscapes. Human Ecology, 38 (3), 401-414.

Nelson, M., Natcher, D.C., \& Hickey, C.G. (2005). Social and economic barriers to subsistence harvesting in a northern Alberta aboriginal community. Anthropologica, 47 (2), 289-301.

Parlee, B.L., Geertsema, K., \& Willier, A. (2012). Social-ecological thresholds in a changing boreal landscape: Insights from Cree knowledge of the lesser Slave Lake region of Alberta, Canada. Ecology \& Society, 17 (2), 1-13.

Settee, P. (2011). The strength of women: Ahkamêyimowak. Regina: Coteau Books.

Turner, N. J., Davidson-Hunt, I.J., \& O'Flaherty, M. (2003). Living on the edge: Ecological and cultural edges as sources of diversity for social-ecological resilience. Human Ecology, 31 (3), 439-461.

Uprety, Y., Asselin, H., Dhakal, A., \& Julien, N. (2012). Traditional use of medicinal plants in the boreal forest of Canada: review and perspectives. Journal of Ethnobiology and Ethnomedicine, 8 (7), 1-14. 